\section{(1) \\ CrossMark}

\title{
The effects of lung volume reduction treatment on diffusing capacity and gas exchange
}

\author{
Marlies van Dijk $\oplus^{1}{ }^{1}$, Karin Klooster ${ }^{1}$, Nick H.T. Ten Hacken ${ }^{1}$, Frank Sciurba², \\ Huib. A.M. Kerstjens (i) ${ }^{1}$ and Dirk-Jan Slebos (i) ${ }^{1}$
}

Affiliations: ${ }^{1}$ University of Groningen, Dept of Pulmonary Diseases, University Medical Center Groningen, Research Institute for Asthma and COPD Groningen, Groningen, The Netherlands. ${ }^{2}$ Division of Pulmonary and Critical Care Medicine, University of Pittsburgh School of Medicine, Pittsburgh, PA, USA.

Correspondence: Marlies van Dijk, Dept of Pulmonary diseases, AA11, University Medical Center Groningen, PO Box 30001, 9700 RB Groningen, The Netherlands. E-mail: m.van.dijk05هumcg.nl

@ERSpublications

This review shows that lung volume reduction treatment can lead to a small increase in $D_{\mathrm{LCO}}$, but on average no important changes in gas exchange. Improvement in $V^{\prime}$ inhomogeneity and $V^{\prime} / Q^{\prime}$ mismatch may be explanations for the improvement in $D_{\mathrm{LCO}}$. https://bit.ly/3fsDqf3

Cite this article as: van Dijk M, Klooster K, Ten Hacken NHT, et al. The effects of lung volume reduction treatment on diffusing capacity and gas exchange. Eur Respir Rev 2020; 29: 190171 [https://doi.org/ $10.1183 / 16000617.0171-2019]$.

ABSTRACT Lung volume reduction (LVR) treatment in patients with severe emphysema has been shown to have a positive effect on hyperinflation, expiratory flow, exercise capacity and quality of life. However, the effects on diffusing capacity of the lungs and gas exchange are less clear.

In this review, the possible mechanisms by which LVR treatment can affect diffusing capacity of the lung for carbon monoxide $\left(D_{\mathrm{LCO}}\right)$ and arterial gas parameters are discussed, the use of $D_{\mathrm{LCO}}$ in LVR treatment is evaluated and other diagnostic techniques reflecting diffusing capacity and regional ventilation $\left(V^{\prime}\right) /$ perfusion $\left(Q^{\prime}\right)$ mismatch are considered.

A systematic review of the literature was performed for studies reporting on $D_{\mathrm{LCO}}$ and arterial blood gas parameters before and after LVR surgery or endoscopic LVR with endobronchial valves (EBV). $D_{\text {LCO }}$ after these LVR treatments improved (40 studies, $\mathrm{n}=1855$ ) and the mean absolute change from baseline in $\%$ predicted $D_{\mathrm{LCO}}$ was $+5.7 \%$ (range $-4.6 \%$ to $+29 \%$ ), with no real change in blood gas parameters. Improvement in $V^{\prime}$ inhomogeneity and $V^{\prime} / Q^{\prime}$ mismatch are plausible explanations for the improvement in $D_{\text {LCO }}$ after LVR treatment.

\section{Introduction}

Lung volume reduction (LVR) surgery in patients with diffuse emphysema was first described as early as 1957 by Brantigan et al. [1]. Although this treatment gave significant clinical improvement in three quarters of treated patients, the high mortality rate prevented this surgical technique from becoming a regularly used treatment option for many decades. In the 1990s there was a revival of LVR surgery, which started with the reports of COOPER and colleagues [2,3] who performed bilateral partial lung resection and documented improvement in lung function and symptoms with a mortality rate of 4\%. In 2003 the large multicenter National Emphysema Treatment Trial (NETT) demonstrated improvement in lung function, dyspnoea, exercise capacity and survival with LVR surgery compared to medical treatment, mainly in the

\section{This article has supplementary material available from err.ersjournals.com}

Provenance: Submitted article peer reviewed

Received: 6 Dec 2019 | Accepted after revision: 19 May 2020

Copyright (CERS 2020. This article is open access and distributed under the terms of the Creative Commons Attribution Non-Commercial Licence 4.0. 
subset of patients with upper lobe dominant emphysema and low baseline exercise capacity [4]. A high risk subgroup of patients was identified with baseline \% predicted forced expiratory volume in $1 \mathrm{~s}\left(\mathrm{FEV}_{1}\right)$ of $\leqslant 20 \%$, combined with either a homogeneous distribution of emphysema or \% predicted diffusing capacity of the lung for carbon monoxide $\left(D_{\mathrm{LCO}}\right)<20 \%$ [4]. Important post-operative complications of LVR surgery are prolonged air leak, pneumonia, prolonged mechanical ventilation and reoperation $[2,3]$.

The substantial morbidity and mortality accompanying LVR surgery elicited interest in developing less invasive endobronchial techniques for lung volume reduction. In 2002, TomA et al. [5] reported the first pilot study in which endobronchial valves (EBVs) are placed endoscopically in patients with severe emphysema. Results were promising and in recent years multiple randomised clinical trials have been published in which EBV placement shows statistically significant and clinically relevant effects on lung function, exercise capacity and quality of life [6-10]. In the current Global Initiative for Chronic Obstructive Lung Disease (GOLD) guidelines, EBV placement is recognised as an additional treatment option in a specific group of patients having emphysema, hyperinflation and proven absence of collateral ventilation [11].

The main effect of LVR treatment is thought to be improved lung compliance due to better matching of the size of the lungs to the size of the thorax containing them. This in turn results in improved lung elastic recoil at similar thoracic inspiratory volume, better expiratory airflow and reduced dynamic and static hyperinflation [12]. Indeed, the effects of LVR treatment on $\mathrm{FEV}_{1}$, vital capacity (VC), total lung capacity (TLC) and residual volume (RV) are well established. However, much less is known about the effect of LVR treatment on the diffusing capacity of the lungs and on gas exchange.

In this review, we summarise results from studies reporting the effects of LVR surgery and endoscopic LVR with EBVs on $D_{\mathrm{LCO}}$ and gas exchange parameters. Furthermore, we propose mechanisms by which LVR treatment can affect both $D_{\mathrm{LCO}}$ and gas exchange, and discuss the use of $D_{\mathrm{LCO}}$ measurement in selecting patients for LVR treatments. Finally, we consider the suitability of alternative techniques for measuring diffusing capacity and regional ventilation $\left(V^{\prime}\right) /$ perfusion $\left(Q^{\prime}\right)$ mismatch in selecting patients with emphysema for LVR treatment.

\section{Diffusing capacity of the lung for carbon monoxide}

The method to measure lung diffusion through carbon monoxide uptake during a single breath was developed by KROGH et al. over 100 years ago [13]. In 1957, this method was modified by OGILvIE et al. [14] to measure the pulmonary diffusing capacity for carbon monoxide. This method, using modernised rapid gas analysis, remains the most common standard for measurement of lung diffusion throughout the world [15]. The patient is asked to exhale maximally and then slowly inspire to TLC and perform a $10 \mathrm{~s}$ breath-hold manoeuvre. During inspiration, the patient inhales a test gas which contains a known low concentration of carbon monoxide (approximately 0.03\%) and an inert tracer gas (e.g. helium). By measuring the concentration of the exhaled carbon monoxide and tracer gas the $D_{\mathrm{LCO}}$ can be calculated. The concentration difference in carbon monoxide is used to calculate a rate constant for alveolar-capillary carbon monoxide transfer, the transfer coefficient of the lung for carbon monoxide $\left(K_{\mathrm{CO}}\right)$. The concentration difference in the tracer gas represents the dilutional effect used to calculate the alveolar volume $\left(V_{\mathrm{A}}\right)$ [15].

\section{Diffusing capacity in patients with emphysema}

In 1977, WAGNER et al. [16] showed by extensive testing with multiple inert gasses that emphysema is associated with a significant high regional $V^{\prime} / Q^{\prime}$ ratio. They attributed the degree of hypoxemia in their group to $V^{\prime} / Q^{\prime}$ mismatch and shunting, leading to the conclusion that diffusing impairment plays no role in hypoxemia in resting patients with emphysema. As there was no imaging available in this study, it cannot be concluded that this pattern is represented throughout the heterogeneous spectrum of patterns and severity of lung parenchymal emphysema and airway involvement.

In fact, emphysema is associated with an impaired $D_{\mathrm{LCO}}$ and a clear inverse linear relationship has been demonstrated between $D_{\text {LCO }}$ and the severity of emphysema on computed tomography (CT) [17]. Furthermore, in chronic obstructive pulmonary disease (COPD) there is an association between $D_{\mathrm{LCO}}$ and mortality [18], and decreased $D_{\text {LCO }}$ is associated with an increased likelihood of reduced arterial oxygen tension $\left(P_{\mathrm{aO}_{2}}\right)$ during rest and with exertion $[19,20]$. The reason $D_{\mathrm{LCO}}$ is impaired in patients with emphysema is thought to be due to the loss of gas exchange surface. Pulmonary microvascular blood flow has been shown to be reduced in mild to severe COPD and is related to emphysema severity on the chest CT scan [21]. Pathophysiologically, the reduced quantity of gas exchange surface can be interpreted as a diffusing impairment. However, it can also be interpreted as a $V^{\prime} / Q^{\prime}$ mismatch where there is reduced capillary blood volume in areas of largely preserved $V^{\prime}$ (i.e. high $V^{\prime} / Q^{\prime}$ ratio). Reality is probably more complex than this however, as $V^{\prime}$ is also affected in COPD. For example, air trapping or airflow obstruction can result from bronchitis, small airways disease or emphysema [22]. $V^{\prime} / Q^{\prime}$ disturbances have 
been shown to be common even in the early stages of COPD [23]. Furthermore, regional heterogeneity is likely to result in hyperinflated regions impacting $V^{\prime}$ or $Q^{\prime}$ in adjacent lung regions.

The reliability of $D_{\text {LCO }}$ testing in emphysema, in order to estimate the anatomical loss of gas exchange area, can be affected in several ways (figure 1). First, inhomogeneous $V^{\prime}$ may be present due to the presence of both airways disease and/or emphysema [24, 25]. Thompson et al. [24] developed mathematical models in which they tested different types of inhomogeneous $V^{\prime}$ and, when there was inhomogeneity of inspired volume or end-expiratory volume, $D_{\mathrm{LCO}}$ was underestimated. In contrast, inhomogeneity of alveolar compartment size led to an overestimation of $D_{\mathrm{LCO}}$. In the lungs of a patient with COPD, these types of inhomogeneous $V^{\prime}$ can co-exist, which makes it difficult to predict the combined effect of these errors on measured $D_{\mathrm{LCO}}$.

Methodological issues in COPD patients can affect the reliability of the measurements. For example, patients with COPD can have difficulty with the $10 \mathrm{~s}$ breath-hold manoeuvre. In contrast to healthy subjects, a shorter breath-holding time decreases $D_{\text {LCO }}$ in patients with airflow obstruction and emphysema [26]. On the other hand, the reduced expiratory flow rate in patients with COPD may lead to an overestimation of $D_{\mathrm{LCO}}$ [27]. The $V_{\mathrm{A}}$ /TLC ratio can help to identify the maldistribution of inspired gas and poor mixing of gases in the lung. Normally the $V_{\mathrm{A}} / \mathrm{TLC}$ ratio exceeds 0.85 , however, in patients with COPD this ratio is often much lower, indicating that $D_{\mathrm{LCO}}$ measurement might be influenced by inhomogeneous $V^{\prime}$, such that potentially functional lung units are not involved in gas distribution $[28,29]$.

\section{Reported effects of LVR surgery and endoscopic LVR on $D_{\text {Lco }}$ and gas exchange}

We performed a literature search for studies which investigated either LVR surgery or endoscopic LVR with EBVs; specifically studies that reported on $D_{\mathrm{LCO}}$, alveolar-arterial oxygen tension difference $\left(P_{\mathrm{A}-\mathrm{aO}_{2}}\right.$; alveolar-arterial oxygen gradient), arterial carbon dioxide tension $\left(P_{\mathrm{aCO}_{2}}\right)$ and $P_{\mathrm{aO}}$ before and after LVR treatment. Since $V^{\prime}$ inhomogeneity is common in COPD and can lead to an overestimation of $K_{\mathrm{CO}}$ [30], we excluded this parameter from our search strategy (see supplementary material).

Information on baseline and follow-up values for \% predicted $D_{\text {LCO }}$ was given in 41 studies, 26 studies regarding LVR surgery (figure $2 \mathrm{a}$, supplementary table $\mathrm{S} 1$ ) and 15 studies with EBVs (figure 2b, supplementary table $\mathrm{S} 2$ ). In five studies, $D_{\text {LCO }}$ values where only given in absolute values (supplementary table S3). In all but four studies there was a mean increase in $D_{\text {LCO }}$ after treatment, which was statistically significant in 19 studies. The weighted mean increase in \% predicted $D_{\text {LCO }}$ was $5.7 \%$ (range $-4.6 \%$ to $29 \%$ ). The suggested minimal clinically important difference (MCID) for $D_{\text {LCO }}$ is a relative increase in $\%$ predicted $D_{\text {LCO }}$ of $11 \%$ [31]. The weighted relative increase in $\%$ predicted $D_{\text {LCO }}$ was $18.4 \%$, with 24 out of 40 studies reporting an increase larger than $11 \%$.

Ten studies that reported on a standard deviation, range or interquartile range for change in $D_{\text {LCO }}$ showed a very broad distribution (supplementary table S4). This implies that even though there may be a (small) positive change in $D_{\text {LCO }}$ after LVR treatment on average, the effects on an individual level can be variable, ranging from a negative effect to a large positive effect. Unfortunately, due to the various ways in which the data was reported, it could not be calculated whether this increase was statistically significant.

a)

Factors influencing $D_{\mathrm{LCO}}$ in COPD

Technical factors

Reduced breath holding time Reduced VC

$V^{\prime} / Q^{\prime}$ mismatch

(1) Airflow obstruction

2 Hyperinflation/airtrapping Reduced $\mathrm{CO}$

(3) Loss of gas exchange surface Alveoli and capillaries

Other

$$
\begin{aligned}
& \mathrm{PH} \\
& \text { Increased } \mathrm{Hb}_{\mathrm{CO}} \text { (in smoking) } \\
& \text { Anaemia }
\end{aligned}
$$

b)



Factors influencing $D_{\mathrm{LCO}}$ after LVR treatment

$$
\begin{aligned}
& \text { Technical factors } \\
& \text { Improved VC } \\
& \text { Change in V'/Q' } \\
& \text { 4 Improved airflow obstruction } \\
& \text { Improved airway tethering } \\
& \text { 5 Reduced hyperinflation/ } \\
& \text { airtrapping } \\
& \text { 6) Additional loss of gas exchange } \\
& \text { surface (LVR effect) } \\
& \text { Hypothetical } \\
& \text { Increased breath holding time? } \\
& \text { Improved CO? }
\end{aligned}
$$

FIGURE 1 a) Factors influencing the measurement of diffusing capacity of the lung for carbon monoxide ( $\left.D_{\text {Lco }}\right)$ in patients with chronic obstructive pulmonary disease (COPD). b) Factors influencing $D_{\text {LCo }}$ after lung volume reduction (LVR) treatment. VC: vital capacity; $V^{\prime} / Q^{\prime}$ : ventilation/perfusion ratio; $\mathrm{CO}$ : cardiac output; $\mathrm{PH}$ : pulmonary hypertension; $\mathrm{Hb}_{\mathrm{CO}}$ : carboxyhaemoglobin. 
a)

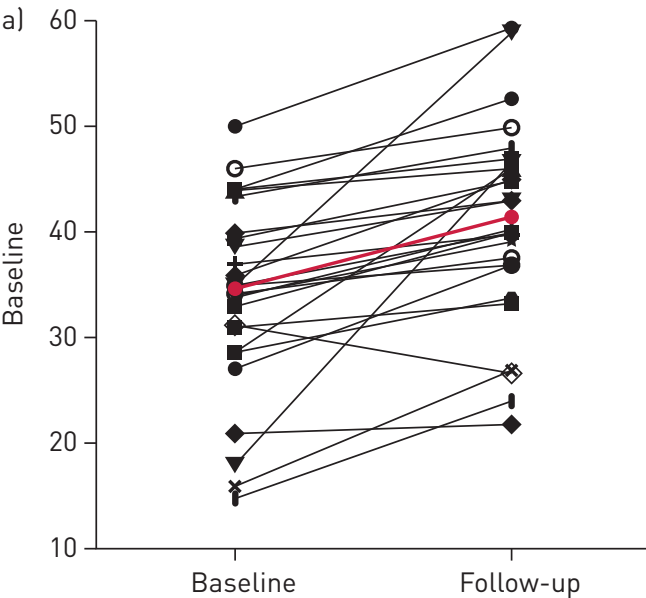

b)

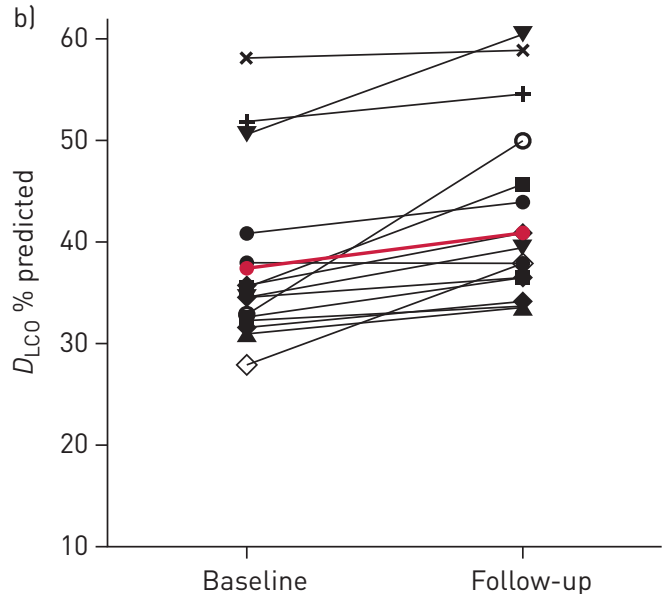

FIGURE 2 a) Change in \% predicted diffusing capacity of the lung for carbon monoxide $\left(D_{\text {LCo }}\right)$ from before to after lung volume reduction (LVR) surgery, as reported in 25 studies. b) Change in \% predicted $D_{\text {Lco }}$ from before to after endoscopic LVR with endobronchial valves (EBV), as reported in 15 studies. Weighted mean change is represented by the red line.

In 35 studies, information was given on $P_{\mathrm{aO}}$ and $P_{\mathrm{aCO}}$ before and after treatment (table 1). There was a weighted mean improvement in $P_{\mathrm{aO}_{2}}$ of $+0.64 \mathrm{kPa}$ (range $-0.40 \mathrm{kPa}$ to $+1.30 \mathrm{kPa}$ ) and a weighted mean decrease in $P_{\mathrm{aCO}_{2}}$ of $-0.31 \mathrm{kPa}$ (range $-0.90 \mathrm{kPa}$ to $+0.60 \mathrm{kPa}$ ). A total of 36 studies were found in which the $P_{\mathrm{A}-\mathrm{aO}}$ gradient was either reported or where it was possible to calculate it from values given for $P_{\mathrm{aO}_{2}}$ and $P_{\mathrm{aCO}}$ before and after treatment (table 1, supplementary table S5). The following formula was used to calculate the $P_{\mathrm{A}-\mathrm{aO}}$ gradient: $\left(\left(F_{\mathrm{IO}_{2}}\right) \cdot\right.$ (atmospheric pressure- $\mathrm{H}_{2} \mathrm{O}$ pressure) $\left.-\left(P_{\mathrm{aCO}_{2}} / 0.8\right)\right)-P_{\mathrm{aO}_{2}}$ (where inspiratory oxygen fraction $\left(F_{\mathrm{IO}_{2}}\right)$ was assumed to be $21 \%$ (room air), atmospheric pressure was assumed to be $101.33 \mathrm{kPa}$ and $\mathrm{H}_{2} \mathrm{O}$ pressure was assumed to be $6.3 \mathrm{kPa}$ ) [32]. The weighted mean change in $P_{\mathrm{A}-\mathrm{aO}}$ gradient after treatment was $-0.18 \mathrm{kPa}$ (range $-1.10 \mathrm{kPa}$ to $1.60 \mathrm{kPa}$ ). Statistical significance is unknown for these values; however, the wide range shows that there is great variation in response to LVR treatment for $P_{\mathrm{A}-\mathrm{aO}}$ gradient.

Fifteen studies reported on $\%$ predicted $D_{\mathrm{LCO}}$ and $P_{\mathrm{aO}_{2}}$ combined with $P_{\mathrm{aCO}_{2}}$ (supplementary table S6). While all but one study showed a positive effect on $D_{\mathrm{LCO}}$, the $P_{\mathrm{A}-\mathrm{aO}}$ gradient was stable or increased in four studies. There was no significant correlation between change in $D_{\mathrm{LCO}}$ and $P_{\mathrm{A}-\mathrm{aO}}$ gradient.

\section{Potential mechanisms by which LVR surgery and endoscopic LVR can influence gas exchange and $D_{\text {Lco }}$ testing}

As shown in figure 1, the measurement of $D_{\mathrm{LCO}}$ in COPD patients can be influenced by several mechanisms, such as reduction in gas exchange surface, an altered $V^{\prime} / Q^{\prime}$ ratio, $V^{\prime}$ inhomogeneity (e.g. air trapping) and pulmonary hypertension $(\mathrm{PH})$. The same mechanisms can also influence gas exchange.

When LVR treatment is performed, these mechanisms may change and can therefore alter the outcome of $D_{\text {LCO }}$ measurement as well as functional gas exchange. The ultimate effect on diffusing capacity and gas exchange is likely related to the balance of these mechanisms. Due to patient and treatment heterogeneity, the net result of LVR treatment may vary greatly, as has been shown above in the results section.

TABLE 1 Change in diffusing capacity and gas exchange parameters after lung volume reduction (LVR) treatment

\begin{tabular}{lccccc} 
Parameter & Studies $\mathbf{n}$ & Patients $\mathbf{n}$ & Before LVR & After LVR & Difference \\
\hline $\boldsymbol{D}_{\mathrm{Lco}} \%$ predicted & 41 & 1864 & 35.6 & 41.3 & +5.7 \\
$\boldsymbol{P}_{\mathrm{aO}_{2}} \mathbf{k P a}$ & 35 & 1375 & 8.72 & 9.36 & +0.64 \\
$\boldsymbol{P}_{\mathrm{aco}_{2}} \mathbf{k P a}$ & 35 & 1375 & 5.53 & 5.22 & -0.31 \\
$\boldsymbol{P}_{\mathrm{A-aO}} \mathbf{~} \mathbf{P a}$ & 36 & 1408 & 4.23 & 4.05 & -0.18 \\
\hline
\end{tabular}

$D_{\mathrm{Lco}}$ : diffusing capacity of the lung for carbon monoxide; $P_{\mathrm{aO}_{2}}$ : arterial oxygen tension; $P_{\mathrm{aco}}$ : arterial carbon dioxide tension; $P_{\mathrm{A}_{-} \mathrm{O}_{2}}$ : alveolar-arterial oxygen tension difference lalveolar-arterial oxygen gradient). 
The impact of LVR treatment on $D_{\text {LCO }}$ was investigated in an animal model where LVR surgery was performed on rabbits with emphysema. Resecting more than $30 \%$ of total lung tissue led to a decrease in $D_{\text {LCO; }}$ however, there was still a positive effect on spirometry and RV [33]. This suggests that the volume of lung tissue which can be resected or blocked by EBVs can be an important limiting factor.

In another study, in 14 patients undergoing LVR surgery, changes in gas exchange were investigated with the multiple inert-gas elimination technique. In this study, change in $P_{\mathrm{aO}}$ was found to be explained mostly by improved $V^{\prime} / Q^{\prime}$ inequality, whereas changes in $P_{\mathrm{aCO}_{2}}$ were related to variables concerning static hyperinflation and airflow potential [34].

The following questions may be useful when thinking about the effects of LVR surgery and endoscopic LVR on $D_{\text {LCO }}$ and gas exchange: 1 . What was the regional $V^{\prime}-Q^{\prime}$ distribution in the lung section(s) that have been surgically removed or blocked by EBVs and in the remaining lung sections? 2. In what way does overall $V^{\prime}$ change after LVR treatment? 3. In what way does overall lung $Q^{\prime}$ change after LVR treatment? 4. Was there compression of the removed or blocked lung tissue on the remaining lung sections? 5. Are there differences between LVR surgery and endoscopic LVR with EBVs influencing the treatment effect?

Question 1: What was the regional $V^{\prime}-Q^{\prime}$ distribution in the lung section(s) that have been surgically removed or blocked by EBVs and in the remaining lung sections?

With respect to $V^{\prime}-Q^{\prime}$ distribution in LVR treatment, AlBerT et al. [35] suggested four different scenarios in LVR surgery, with different outcomes on gas exchange. If an area with a high $V^{\prime} / Q^{\prime}$ ratio is resected, more $V^{\prime}$ could go to the remaining lung sections. If there is already a high $V^{\prime} / Q^{\prime}$ ratio in these lung sections, the overall effect will be an even worse $V^{\prime} / Q^{\prime}$ distribution. However, if there is a low $V^{\prime} / Q^{\prime}$ ratio before treatment, an increase in $V^{\prime}$ would lead to a better $V^{\prime} / Q^{\prime}$ distribution and improvement of gas exchange. When resecting an area with a low $V^{\prime} / Q^{\prime}$ ratio, more blood flow will go to the remaining lung sections. If the remaining lung sections have a high $V^{\prime} / Q^{\prime}$ ratio this can lead to a better $V^{\prime} / Q^{\prime}$ distribution. Conversely, an increase in blood flow in lung sections with an already low $V^{\prime} / Q^{\prime}$ ratio leads to a worse $V^{\prime} / Q^{\prime}$ distribution.

Patients who are selected for LVR are typically patients with severe emphysema. As mentioned earlier, these patients are shown to have considerable regions of high $V^{\prime} / Q^{\prime}$ ratio [16]. As such, the most likely scenario is probably the removal or blockage of areas with a high $V^{\prime} / Q^{\prime}$ ratio, because in general areas with severe emphysema are treated. The effect this has on gas exchange depends on the regional $V^{\prime} / Q^{\prime}$ mismatch in the remaining lung sections. The best results for $P_{\mathrm{aO}}$ can be expected when the remaining lung sections have low $V^{\prime} / Q^{\prime}$ distribution, which is more likely to be present in heterogeneous emphysema. However, it is important to note that in the above mentioned scenarios it is assumed that respiratory minute ventilation and cardiac output $(\mathrm{CO})$ are unchanged by LVR surgery.

\section{Question 2: In what way does overall V' change after LVR treatment?}

Several studies [36-39] have analysed the effect of LVR surgery on respiratory minute volume and alveolar ventilation, including two studies by the group of Albert [36, 37]. All these studies show an increase in respiratory volume and tidal volume during exercise, as well as a decrease in breathing frequency, although no such changes are reported at rest.

In our analysis, we found that there was an increase in $P_{\mathrm{aO}_{2}}$ and a decrease in $P_{\mathrm{aCO}}$ in five studies [35, 40-43], while the $P_{\mathrm{A}-\mathrm{aO}}$ gradient remained stable at rest or increased. This suggests that respiratory minute volume at rest can indeed increase after LVR treatment.

Question 3: In what way does overall lung Q' change after LVR treatment?

Reports on change in CO after LVR surgery have shown mixed effects [44-46]. When LVR surgery started to become a treatment for patients with severe emphysema, one of the main concerns was development of postoperative $\mathrm{PH}$ and, consequently, reduced cardiac function due to reduction of the pulmonary vascular bed.

One prospective study did show an increase in pulmonary artery systolic pressure, but this was not accompanied by a reduction in cardiac function [46]. Other studies showed no change in mean pulmonary pressure $[44,45]$. Furthermore, improvement in right-ventricular function after LVR surgery was demonstrated in a prospective trial [41]. The varying responses of pulmonary hemodynamics to LVR surgery demonstrate the heterogeneity of both patient-related factors and surgical treatment effects.

An inverse relation between static hyperinflation and heart size has been established in patients with COPD [47]. More severe hyperinflation was associated with a smaller heart size, which in turn was associated with impaired left-ventricular diastolic filling and impaired right-ventricular function [47]. Recently, a study was published where treatment with a long-acting $\beta_{2}$-agonist-long-acting muscarinic antagonist combination 
resulted in an increase in cardiac index in patients with COPD and hyperinflation [48]. As such, CO may hypothetically increase if LVR treatment successfully diminishes static hyperinflation. However, this has not consistently been demonstrated in clinical trials so far, probably due to individual patient variation and differences in intervention techniques.

\section{Question 4: Was there compression of the removed or blocked lung tissue on the remaining lung} sections?

Whether there is compression on the surrounding lung tissue by the treated lung tissue is more difficult to assess in a research setting. However, when assessing a chest CT scan of a patient with severe emphysema in clinical practice, compression of lung tissue by a hyperinflated lobe is sometimes clear to see. When treating this hyperinflated lobe, either endobronchially or surgically, the compressed lung tissue will exhibit improved $V^{\prime}$, which is likely to have a positive effect on gas exchange. The extent of this effect will depend on the amount and functional quality of the compressed lung tissue.

\section{Question 5: Are there differences between LVR surgery and endoscopic LVR with EBVs} influencing the treatment effect?

It seems likely that LVR surgery and endoscopic LVR with EBVs have largely the same average effects on $D_{\mathrm{LCO}}$ and gas exchange, and also exhibit similar individual patient variations in response; however, there are also important differences. First, the lung tissue (including blood vessels) is completely removed following surgery. Whereas, in successful endoscopic LVR, there is an atelectasis of the lung lobe where there may still be some remaining blood flow present. When atelectasis of the left lung was induced in healthy dogs, a significant reduction in the percentage of the total blood flow was measured in the atelectatic lung. The maximum reduction, from $43 \%$ to $12 \%$ of total blood flow, was measured after $60 \mathrm{~min}$ and remained unchanged for the total of $4 \mathrm{~h}$ that the atelectasis existed [49]. A more recent study in human emphysema used lung scintigraphy to assess $V^{\prime}$ and $Q^{\prime}$ over both the target lobe and untreated lobes before and 8 weeks after EBV placement [50]. This study showed a mean $43 \%$ reduction of $Q^{\prime}$ in the target lobe, with significant increases in $Q^{\prime}$ at the contralateral side. It should be noted that it is difficult to assess the reduction in blood flow in the target lobe very precisely with this technique. As such, some shunting probably remains in the atelectatic target lobe, but the precise amount of shunting and its clinical relevance are not known.

Surgical lobectomies for LVR are also presently performed; however, in the majority of published trials surgery is mainly performed bilaterally [1-4], whereas endoscopic LVR with EBVs is performed unilaterally [6-10]. Furthermore, lung tissue resection is not confined to anatomical borders, so the surgeon can resect the most emphysematous tissue on both sides. Endoscopic LVR with EBVs is confined to one or at most two lobes when the middle lobe is involved. Less emphysematous lung tissue within the target lobe will be collapsed as well, which could have a less optimal effect on gas exchange and $D_{\text {LCO }}$.

\section{The use of $D_{\text {Lco }}$ testing to select patients for LVR treatment}

Currently, it is common practice not to treat patients with very low $D_{\text {LCO }}$ given the high risk of death as identified in the NETT [4]. This is in line with the higher mortality rates generally observed in COPD patients with low $D_{\text {LCO }}[18]$. However, excluding some patients with very low $D_{\text {LCO }}$ may lead to the exclusion of patients who may actually benefit from LVR treatment. Two retrospective analyses [51, 52] have shown no increased mortality and a positive effect on $\mathrm{FEV}_{1}, \mathrm{RV}$ and $D_{\mathrm{LCO}}$ after LVR surgery in patients fulfilling the NETT high risk criteria. Therefore, using $D_{\text {LCO }}$ as a measurement to select patients for LVR treatment appears to have its limitations.

The general assumption is that $D_{\text {LCO }}$ reflects the quality and quantity of the alveolar-capillary gas-exchange surface. Therefore, in the light of LVR (where we sacrifice part of the gas-exchange area in favour of mechanical advantages) it seems rational to use $D_{\mathrm{LCO}}$ testing for risk assessment (i.e. is there enough gas-exchange surface left to sacrifice a part of it?). An arbitrary cut-off point (such as \% predicted $D_{\text {LCO }}<20 \%$ ) could then indicate the tipping point where the risk for respiratory failure becomes too large. This assumption would be supported by a clear reduction in $D_{\text {LCO }}$ after LVR treatment. However, with our meta-analysis we have demonstrated that $D_{\text {LCO }}$ frequently improves after LVR treatment. As such, the assumption that $D_{\text {LCO }}$ reflects alveolar gas-exchange capability is apparently not (completely) valid, at least in severe emphysema patients. Improved $V^{\prime}$ and $Q^{\prime}$ of the adjacent and other lung lobe(s) are probably responsible for the observed improvements in $D_{\text {LCO }}$ after successful LVR treatment. Consequently, we should use the $D_{\text {LCO }}$ test not only as a tool to assess risk but also as a tool to assess potential benefit, which requires a switch in thinking. The question then arises as to how $D_{\text {LCO }}$ should be used to discriminate between patients who might benefit from LVR treatment and patients who are at risk for developing respiratory failure after treatment. The answer is probably that $D_{\mathrm{LCO}}$ as a single measurement 
at baseline is too unreliable. Using $D_{\mathrm{LCO}}$ in combination with other variables, such as $\mathrm{FEV}_{1}$, arterial blood gas analysis and distribution of lung emphysema seems attractive. However, at this moment in time we do not have validated algorithms that may support individual decision making. We speculate that low FEV 1 easily associates with false low $D_{\mathrm{LCO}}$ measurements and as such excluding subjects solely on the basis of low $\mathrm{FEV}_{1}$ and low $D_{\mathrm{LCO}}$ is not recommended. Low $D_{\mathrm{LCO}}$ in combination with low $P_{\mathrm{aO}}$ seems unattractive for LVR treatment unless a patient has significant heterogeneous emphysema, in which case we believe LVR can still be considered because a low $V^{\prime} / Q^{\prime}$ ratio in an adjacent lobe can be improved on treatment. If patients have low $D_{\mathrm{LCO}}$, high $P_{\mathrm{aCO}_{2}}$ and homogeneous emphysema, we believe LVR is less attractive because a high $V^{\prime} / Q^{\prime}$ ratio in an adjacent lobe can deteriorate (see question 1 above).

To summarise, we recommend the use of $D_{\mathrm{LCO}}$ not only as a tool to assess risk for respiratory failure but also as a tool to assess potential benefit from LVR treatment. However, as individual decision making is still difficult for many emphysema patients with low $D_{\text {LCO }}$, we clearly need additional diagnostic tools that investigate other aspects of gas exchange.

\section{Are there better diagnostic tests to select patients?}

Diagnostic tests which can accurately reflect the total quantity of gas-exchange surface and/or regional $V^{\prime} / Q^{\prime}$ ratios in the lung would be helpful in assessing the probability of a successful LVR treatment (i.e. one which results in a reduction of hyperinflation while preserving or even improving gas exchange).

\section{Diffusing capacity of the lung (gas-exchange surface)}

As measuring $D_{\mathrm{LCO}}$ by the single-breath method $\left(D_{\mathrm{LCO}} \mathrm{SB}\right)$ can be technically difficult in COPD patients and the outcome $D_{\mathrm{LCO}}$ measurement is influenced by $V^{\prime}$ inhomogeneity, we assessed whether there are better techniques to reflect diffusing capacity of the lung in these patients.

First, the use of a real-time gas-analyzer system, in which both the concentration of tracer gas and that of carbon monoxide are measured continuously, has been shown to provide a better estimate of $V_{\mathrm{A}}$ [15], which is notoriously difficult in patients with COPD [29]. Techniques that are rarely used include the so-called "rebreathing" method and the "open-circuit" method. As with $D_{\mathrm{LCO}} \mathrm{SB}$, both were found to be influenced by $V^{\prime}$ inhomogeneity [24]. Three-equation $D_{\mathrm{LCO}}$ is a variant of the single-breath method where three equations are used, one for each part of the single-breath manoeuvre (inhalation, breath-holding and exhalation) [53]. In healthy persons, three-equation $D_{\mathrm{LCO}}$ remained constant despite variations in duration of breath-holding and expiration [53]. Unfortunately, a shorter breath-holding time did result in lower $D_{\text {LCO }}$ in patients with emphysema, which the authors related to $V^{\prime}$ maldistribution [26].

Nitric oxide can be used instead of carbon monoxide, thus measuring the diffusing capacity of the lung for nitric oxide $\left(D_{\mathrm{LNO}}\right)$. Nitric oxide can bind approximately 1500 times faster to haemoglobin $(\mathrm{Hb})$ than carbon monoxide and is therefore proposed to be a better representative of the diffusive properties of the alveolar-capillary membrane than $D_{\text {LCO }}[54]$.

There may be some general advantages of $D_{\mathrm{LNO}}$ over $D_{\mathrm{LCO}}$, for example, $D_{\mathrm{LNO}}$ is unaffected by carboxyhaemoglobin $\left(\mathrm{Hb}_{\mathrm{CO}}\right)$, only minimally affected by $\mathrm{Hb}$, and relatively unaffected by $F_{\mathrm{IO}_{2}}$ and ambient pressure [54]. One study investigating heavy smokers showed that the transfer coefficient of the lung for nitric oxide $\left(K_{\mathrm{NO}}\right)$ was slightly more sensitive than $K_{\mathrm{CO}}$ for detecting emphysema [55]. Furthermore, the $D_{\mathrm{LNO}} / D_{\mathrm{LCO}}$ ratio was increased in patients with emphysema; however, no difference between $D_{\mathrm{LCO}}$ and $D_{\mathrm{LNO}}$ was found in the same study [55]. As such, even though there are various techniques for measuring the diffusing capacity of the lungs, in general these techniques have the same shortcomings as $D_{\text {LCO }} \mathrm{SB}$.

\section{Assessing regional $V^{\prime} / Q^{\prime}$ ratio}

Two-dimensional $V^{\prime} / Q^{\prime}$ scintigraphy is an insufficient technique for accurately mapping regional $V^{\prime} / Q^{\prime}$ ratios. However, there are several more advanced imaging techniques which could potentially be used for this purpose. Single-photon emission CT ventilation/perfusion (VQ SPECT) is a technique where three-dimensional $V^{\prime} / Q^{\prime}$ images can be related to CT images [56]. With this technique the percentage of total lung volume, $Q^{\prime}$ and $V^{\prime}$ can be quantified for each lung lobe [57]. Advanced CT scanning, for example four-dimensional CT and multiple-detector CT, can generate functional maps of $V^{\prime}$ and $Q^{\prime}$ [58, 59]. Magnetic resonance imaging can also be used for mapping of $V^{\prime}$ and $Q^{\prime}$, for example by using hyperpolarized xenon $\left({ }^{129} \mathrm{Xe}\right)$ as a tracer gas or via free-breathing Fourier-decomposition MRI [58]. In conclusion, there are several imaging techniques with which regional $V^{\prime} / Q^{\prime}$ can be mapped; however, it is important to note that these techniques are costly and not readily available everywhere. Furthermore, the relatively high radiation dose for four-dimensional CT scanning should be taken into account. 


\section{Summary and future research questions}

On average, LVR surgery and endoscopic LVR with EBVs lead to a small improvement in $D_{\text {LCO }}$ in patients with severe emphysema and hyperinflation, even though there is a reduction in gas-exchange surface. However, there is a great variation in the response on an individual level, probably related to both patient and treatment heterogeneity. We propose that the reason for improved $D_{\mathrm{LCO}}$ is improvement in the $V^{\prime} / Q^{\prime}$ ratio and in $V^{\prime}$ inhomogeneity in the regionally expanded non-targeted lung.

$D_{\text {LCO }}$ is commonly used in screening patients for LVR treatment and may have some value in predicting the eligibility of a patient with severe emphysema for LVR treatment. However, there are several limitations and uncertainties in using this measurement in patients with severe emphysema. Therefore, we recommend measuring $D_{\text {LCO }}$ before LVR treatment, but only in combination with other diagnostic measurements such as arterial blood gas analysis, quantitative CT-analysis of emphysema destruction and Q' scintigraphy.

Other diagnostic methods to assess the quantity of gas-exchange surface and regional $V^{\prime} / Q^{\prime}$ ratios would be helpful, but are currently not readily available. Therefore, further research is needed to obtain more clarity.

Conflict of interest: M. van Dijk has nothing to disclose. K. Klooster reports other funding from PulmonX Inc., outside the submitted work. N.H.T. Ten Hacken has nothing to disclose. F. Sciurba has nothing to disclose. H.A.M. Kerstjens reports research grants from GSK, Novartis and Boehringer, and fees for consultancies on advisory boards from GSK, Novartis and Boehringer, all paid to his institution, outside the submitted work. D-J. Slebos reports grants, personal fees, non-financial support and other funding from PulmonX Inc, during the conduct of the study.

\section{References}

1 Brantigan OC, Mueller E. Surgical treatment of pulmonary emphysema. Am Surg 1957; 23: 789-804.

2 Cooper JD, Trulock EP, Triantafillou AN, et al. Bilateral pneumectomy (volume reduction) for chronic obstructive pulmonary disease. J Thorac Cardiovasc Surg 1995; 109: 106-116.

3 Cooper JD, Patterson GA, Sundaresan RS, et al. Results of 150 consecutive bilateral lung volume reduction procedures in patients with severe emphysema. J Thorac Cardiovasc Surg 1996; 112: 1319-1329.

4 Fishman A, Martinez F, Naunheim K, et al. A randomized trial comparing lung-volume-reduction surgery with medical therapy for severe emphysema. N Engl J Med 2003; 348: 2059-2073.

5 Toma TP, Hopkinson NS, Hillier J, et al. Bronchoscopic volume reduction with valve implants in patients with severe emphysema. Lancet 2003; 361: 931-933.

6 Davey C, Zoumot Z, Jordan S, et al. Bronchoscopic lung volume reduction with endobronchial valves for patients with heterogeneous emphysema and intact interlobar fissures (the BeLieVeR-HIFi study): a randomised controlled trial. Lancet 2015; 386: 1066-1073.

7 Klooster K, ten Hacken NH, Hartman JE, et al. Endobronchial valves for emphysema without interlobar collateral ventilation. $N$ Engl J Med 2015; 373: 2325-2335.

8 Valipour A, Slebos DJ, Herth F, et al. Endobronchial valve therapy in patients with homogeneous emphysema. Results from the IMPACT study. Am J Respir Crit Care Med 2016; 194: 1073-1082.

9 Kemp SV, Slebos DJ, Kirk A, et al. A multicenter randomized controlled trial of Zephyr endobronchial valve treatment in heterogeneous emphysema (TRANSFORM). Am J Respir Crit Care Med 2017; 196: 1535-1543.

10 Criner GJ, Sue R, Wright S, et al. A multicenter randomized controlled trial of Zephyr endobronchial valve treatment in heterogeneous emphysema (LIBERATE). Am J Respir Crit Care Med 2018; 198: 1151-1164.

11 Singh D, Agusti A, Anzueto A, et al. Global strategy for the diagnosis, management, and prevention of chronic obstructive lung disease: the GOLD science committee report 2019. Eur Respir J 2019; 53: 1900164.

12 Fessler HE, Scharf SM, Ingenito EP, et al. Physiologic basis for improved pulmonary function after lung volume reduction. Proc Am Thorac Soc 2008; 5: 416-420.

13 Krogh M. The diffusion of gases through the lung of man. The Journal of Physiology 1914; 49: 271-300.

14 Blakemore WS, Forster RE, Morton JW, et al. A standardized breath holding technique for the clinical measurement of the diffusing capacity of the lung for carbon monoxide. J Clin Invest 1957; 36: 1-17.

15 Graham BL, Brusasco V, Burgos F, et al. 2017 ERS/ATS standards for single-breath carbon monoxide uptake in the lung. Eur Respir J 2017; 49: 1600016.

16 Wagner PD, Dantzker DR, Dueck R, et al. Ventilation-perfusion inequality in chronic obstructive pulmonary disease. J Clin Invest 1977; 59: 203-216.

17 Nambu A, Zach J, Schroeder J, et al. Relationships between diffusing capacity for carbon monoxide ( $\left.D_{\mathrm{LCO}}\right)$, and quantitative computed tomography measurements and visual assessment for chronic obstructive pulmonary disease. Eur J Radiol 2015; 84: 980-985.

18 Boutou AK, Shrikrishna D, Tanner RJ, et al. Lung function indices for predicting mortality in COPD. Eur Respir J 2013; 42: 616-625.

19 Mohsenifar Z, Lee SM, Diaz P, et al. Single-breath diffusing capacity of the lung for carbon monoxide: a predictor of $P_{\mathrm{aO} 2}$, maximum work rate, and walking distance in patients with emphysema. Chest 2003; 123: 1394-1400.

20 Owens GR, Rogers RM, Pennock BE, et al. The diffusing capacity as a predictor of arterial oxygen desaturation during exercise in patients with chronic obstructive pulmonary disease. N Engl J Med 1984; 310: 1218-1221.

21 Hueper K, Vogel-Claussen J, Parikh MA, et al. Pulmonary microvascular blood flow in mild chronic obstructive pulmonary disease and emphysema. The MESA COPD study. Am J Respir Crit Care Med 2015; 192 570-580.

22 Hogg JC. Pathophysiology of airflow limitation in chronic obstructive pulmonary disease. Lancet 2004; 364 : 709-721. 
23 Rodriguez-Roisin R, Drakulovic M, Rodriguez DA, et al. Ventilation-perfusion imbalance and chronic obstructive pulmonary disease staging severity. J Appl Physiol 2009; 106: 1902-1908.

24 Thompson BR, Kim Prisk G, Peyton P, et al. Inhomogeneity of ventilation leads to unpredictable errors in



25 Prediletto R, Fornai E, Catapano G, et al. Assessment of the alveolar volume when sampling exhaled gas at different expired volumes in the single breath diffusion test. BMC Pulm Med 2007; 7: 18.

26 Graham BL, Mink JT, Cotton DJ. Effect of breath-hold time on $D_{\mathrm{LCO}}(\mathrm{SB})$ in patients with airway obstruction. J Appl Physiol 1985; 58: 1319-1325.

27 Graham BL, Mink JT, Cotton DJ. Overestimation of the single-breath carbon monoxide diffusing capacity in patients with air-flow obstruction. Am Rev Respir Dis 1984; 129: 403-408.

28 Hughes JM, Pride NB. Examination of the carbon monoxide diffusing capacity $\left(D_{\mathrm{LCO}}\right)$ in relation to its $K_{\mathrm{CO}}$ and $V_{\mathrm{A}}$ components. Am J Respir Crit Care Med 2012; 186: 132-139.

29 Punjabi NM, Shade D, Wise RA. Correction of single-breath helium lung volumes in patients with airflow obstruction. Chest 1998; 114: 907-918.

30 Cotton DJ, Graham BL. The usefulness of $K_{\mathrm{CO}}$ is questionable. Am J Respir Crit Care Med 2013; $187: 660$.

31 Horita N, Miyazawa N, Kojima R, et al. Minimum clinically important difference in diffusing capacity of the lungs for carbon monoxide among patients with severe and very severe chronic obstructive pulmonary disease. COPD $2015 ; 12: 31-37$

32 Helmholz HF Jr. The abbreviated alveolar air equation. Chest 1979; 75: 748.

33 Chen JC, Brenner M, Huh J, et al. Effect of lung volume reduction surgery on pulmonary diffusion capacity in a rabbit model of emphysema. J Surg Res 1998; 78: 155-160.

34 Cremona G, Barbera JA, Melgosa T, et al. Mechanisms of gas exchange response to lung volume reduction surgery in severe emphysema. J Appl Physiol 2011; 110: 1036-1045.

35 Albert RK, Benditt JO, Hildebrandt J, et al. Lung volume reduction surgery has variable effects on blood gases in patients with emphysema. Am J Respir Crit Care Med 1998; 158: 71-76.

36 Benditt JO, Lewis S, Wood DE, et al. Lung volume reduction surgery improves maximal $\mathrm{O}_{2}$ consumption, maximal minute ventilation, $\mathrm{O}_{2}$ pulse, and dead space-to-tidal volume ratio during leg cycle ergometry. Am J Respir Crit Care Med 1997; 156: 561-566.

37 Homan S, Porter S, Peacock M, et al. Increased effective lung volume following lung volume reduction surgery in emphysema. Chest 2001; 120: 1157-1162.

38 Criner GJ, Belt P, Sternberg AL, et al. Effects of lung volume reduction surgery on gas exchange and breathing pattern during maximum exercise. Chest 2009; 135: 1268-1279.

39 Benditt JO, Wood DE, McCool FD, et al. Changes in breathing and ventilatory muscle recruitment patterns induced by lung volume reduction surgery. Am J Respir Crit Care Med 1997; 155: 279-284.

40 Venuta F, de Giacomo T, Rendina EA, et al. Bronchoscopic lung-volume reduction with one-way valves in patients with heterogenous emphysema. Ann Thorac Surg 2005; 79: 411-416.

41 Sciurba FC, Rogers RM, Keenan RJ, et al. Improvement in pulmonary function and elastic recoil after lung-reduction surgery for diffuse emphysema. N Engl J Med 1996; 334: 1095-1099.

42 Snell GI, Holsworth L, Borrill ZL, et al. The potential for bronchoscopic lung volume reduction using bronchia prostheses: a pilot study. Chest 2003; 124: 1073-1080.

43 Hillerdal G, Lofdahl CG, Strom K, et al. Comparison of lung volume reduction surgery and physical training on health status and physiologic outcomes: a randomized controlled clinical trial. Chest 2005; 128: 3489-3499.

44 Oswald-Mammosser M, Kessler R, Massard G, et al. Effect of lung volume reduction surgery on gas exchange and pulmonary hemodynamics at rest and during exercise. Am J Respir Crit Care Med 1998; 158: 1020-1025.

45 Criner GJ, Scharf SM, Falk JA, et al. Effect of lung volume reduction surgery on resting pulmonary hemodynamics in severe emphysema. Am J Respir Crit Care Med 2007; 176: 253-260.

46 Weg IL, Rossoff L, McKeon K, et al. Development of pulmonary hypertension after lung volume reduction surgery. Am J Respir Crit Care Med 1999; 159: 552-556.

47 Watz H, Waschki B, Magnussen H. Emphysema, airflow obstruction, and left ventricular filling. $N$ Engl J Med 2010; 362: 1638-1639.

48 Hohlfeld JM, Vogel-Claussen J, Biller H, et al. Effect of lung deflation with indacaterol plus glycopyrronium on ventricular filling in patients with hyperinflation and COPD (CLAIM): a double-blind, randomised, crossover, placebo-controlled, single-centre trial. Lancet Respir Med 2018; 6: 368-378.

49 Glasser SA, Domino KB, Lindgren L, et al. Pulmonary blood pressure and flow during atelectasis in the dog. Anesthesiology 1983; 58: 225-231.

50 Pizarro C, Ahmadzadehfar H, Essler M, et al. Effect of endobronchial valve therapy on pulmonary perfusion and ventilation distribution. PLoS One 2015; 10: e0118976.

51 Caviezel C, Schaffter N, Schneiter D, et al. Outcome after lung volume reduction surgery in patients with severely impaired diffusion capacity. Ann Thorac Surg 2018; 105: 379-385.

52 Meyers BF, Yusen RD, Guthrie TJ, et al. Results of lung volume reduction surgery in patients meeting a national emphysema treatment trial high-risk criterion. J Thorac Cardiovasc Surg 2004; 127: 829-835.

53 Graham BL, Mink JT, Cotton DJ. Improved accuracy and precision of single-breath CO diffusing capacity measurements. J Appl Physiol Respir Environ Exerc Physiol 1981; 51: 1306-1313.

54 Zavorsky GS, van der Lee I. Can the measurement of pulmonary diffusing capacity for nitric oxide replace the measurement of pulmonary diffusing capacity for carbon monoxide? Respir Physiol Neurobiol 2017; 241 : 9-16.

55 van der Lee I, Gietema HA, Zanen P, et al. Nitric oxide diffusing capacity versus spirometry in the early diagnosis of emphysema in smokers. Respir Med 2009; 103: 1892-1897.

56 Roach PJ, Schembri GP, Bailey DL. V/Q scanning using SPECT and SPECT/CT. J Nucl Med 2013; 54: 1588-1596.

57 Vanfleteren LEGW, Ojanguren I, Nolan CM, et al. European Respiratory Society International Congress, Paris, 2018: highlights from the Clinical Assembly. ERJ Open Res 2019; 5: 00176-2018.

58 Sheikh K, Coxson HO, Parraga G. This is what COPD looks like. Respirology 2016; 21: 224-236.

59 Alford SK, van Beek EJ, McLennan G, et al. Heterogeneity of pulmonary perfusion as a mechanistic image-based phenotype in emphysema susceptible smokers. Proc Natl Acad Sci USA 2010; 107: 7485-7490. 